\title{
Review: antenatal screening tools to predict postnatal depression generally have low specificity and sensitivity
}

Austin M-P,Lumley J. Antenatal screening for postnatal depression: a systematic review. Acta Psychiatr Scand 2003 Jan, 107:10-7.

\author{
QUESTION: What is the sensitivity and specificity of antenatal screening tools \\ developed to predict depression following childbirth?
}

\section{Source of funding:} not specified.

For correspondence: M-P Austin, Department Liaison Psychiatry, Prince of Wales Hospital, Sydney, Australia.

\section{Design}

Systematic review.

\section{Data sources}

The reviewers searched Medline, Embase, PsycLit, CINAHL, HealthSTAR, recent proceedings of the Marce Society, the Cochrane Library, the UK National Research Register and reference lists of articles and chapters (1980 to August 2001).

\section{Study selection}

Published studies were eligible if they assessed any antenatal instrument, or combination of instruments, to classify women as "at risk" or "not at risk" of postnatal depression during pregnancy. Pregnant women in any care setting were eligible. Papers in languages other than English or French were excluded. The authors included 16 studies from Australia, Demark, Israel, Portugal, Sweden, the United Kingdom, and the United States, with almost 23,000 participants. Most comprised a studyspecific screening tool. Some of the studies were population-based and others were undertaken in teaching hospitals or among low income groups.

\section{Data extraction}

One reviewer extracted data on sensitivity, specificity, positive predictive value, negative predictive value, and positive and negative likelihood ratios. The Edinburgh Postnatal Depression Scale, standardised diagnostic psychiatric interviews, or both were used to assess outcomes.

\section{Main results}

The timing of antenatal screening varied between studies, ranging from 10-12 weeks gestation to 36 weeks. Screening tools also varied. 11 papers used a studyspecific screening test. 7 studies combined a studyspecific questionnaire with a common self report measure such as the General Health Questionnaire, the Beck Depression Inventory, or the Edinburgh Postnatal Depression Scale

The proportion of women identified as "at risk" of postnatal depression during pregnancy ranged between $10-67 \%$. The actual prevalence of postnatal depression ranged between $5.5-31.5 \%$. Most of the antenatal tools in this review had low specificity and sensitivity for predicting postnatal depression (see table).

\section{Conclusions}

There is no evidence to support routine administration of the antenatal screening tools assessed in this review. The authors suggest that a number of factors may contribute to the poor sensitivity of antenatal screening tools for postnatal depression, such as excluding predictive factors (personality, abuse history and postnatal events).
Range of outcomes in studies of antenatal screening tests for postnatal depression

\begin{tabular}{lc} 
Outcome & Range of findings \\
$\begin{array}{l}\text { Proportion depressed after birth whose depression had been predicted } \\
\text { by antenatal screening (sensitivity) }\end{array}$ & 0.23 to 0.79 \\
\hline $\begin{array}{l}\text { Proportion of women predicted to be "at risk" who became depressed } \\
\text { after birth (positive predictive value) }\end{array}$ & 0 to 0.56 \\
\hline $\begin{array}{l}\text { Proportion not depressed after birth, identified as "not at risk" } \\
\text { (specificity) }\end{array}$ & 0.43 to 0.93 \\
\hline $\begin{array}{l}\text { Proportion predicted to be "not at risk" after birth who did not become } \\
\text { depressed (negative predictive value) }\end{array}$ & 0.73 to 0.98 \\
\hline $\begin{array}{l}\text { Proportion with depression identified antenatally as "not at risk" (missed } \\
\text { cases) }\end{array}$ & 21 to $100 \%$ \\
\hline Positive likelihood ratio & 0.67 to 5.43 \\
\hline Negative likelihood ratios & 0.42 to 1.17 \\
\hline
\end{tabular}

\section{COMMENTARY}

Postpartum depression is a traumatic event that can have lasting effects on a woman's confidence in herself as a mother and on her infant's social, emotional and cognitive development. ${ }^{1}$ The introduction of several screening tools to aid early detection and diagnosis of depression has helped to raise awareness among healthcare providers. Preliminary evidence suggests that we would be better able to predict postpartum depression if we considered social and psychological maternal risk factors.

Austin and Lumley's systematic review should compel practitioners to reflect on the causes and consequences of postnatal depression. Recent research suggests that many women are susceptible to psychiatric disorders during pregnancy, with $10-12 \%$ of pregnant women experiencing major depression. Postpartum disorders have recently been incorporated into the DSM-IV. The most vulnerable time for a woman to develop mood disorders is during the postpartum period. During this period, about $12-16 \%$ of women experience depressive disorders.

We must consider whether the type of depression women suffer from in the postnatal period is the same as depression during pregnancy or at other times. The culmination of many factors may ultimately lead to postnatal depression. These factors include a previous history of mood disorders; psychosocial factors such as employment stress, marital discord, or the absence of support from partners, family members and friends; ${ }^{2}$ physically stressful situations during pregnancy and labour such as hormonal fluctuation, anaemia, and use of anaesthesia; and the presence of "maternity blues." I would argue that these aetiological factors suggest that postnatal depression is a specific disorder, not equivalent to depression at other times. ${ }^{3}$ If we are to increase the sensitivity and specificity of predictive tools, screening methods and the study of risk factors may need to be more specific for postnatal depression.

This hypothesis needs further analysis. At present, despite notable attempts such as this review, the causes, consequences and methods of predicting postnatal depression remain uncertain. One thing, though, is clear. Postnatal depression is a major problem. Clinicians have an important role to play in helping women identify and deal with the consequences, including routine screening at 6 weeks postpartum. ${ }^{4}$

JM Sierra Manzano Doctor en Medicina y Cirugía Experto Universitario en Probabilidad y Estadística en Medicina Unidad Docente de Medicina Familiar y Comunitaria, Soria, Spain

1 Nelly C. Postpartum major depresión: detection and treatment. AFP 1999; 59: 2247-62 Cooper P, Murray L Postnatal depression. BMJ 1998; 316: 1884-6.

Fisch RZ, Tadmor OP, Dankner R, Diamant YZ. Postnatal depression: a prospective study of its prevalence, incidence and psychosocial determinants in an Israeli sample. J Obstet Gynae(23: 547-54.

Mryan TL, Wollan P, Yawn BP. Routine screening for postpartum depression.J Fam Pract 2001; 50: 117-22. 